\title{
New Concepts for the Management of INFORMATION RESOURCES
}

\author{
Walter R. Kendall \\ University of North Colorado \\ Greeley, Colorado \\ C. Richard Scott \\ Radford University \\ Radford, Virginia \\ Charles J. Capps III \\ Sam Houston State University \\ Huntsville, Texas
}

Successful mangers of the future are likely to be well-informed opportunists who use information strategically and have the flexibility to respond to opportunities. The success of these managers will be determined by their ability to combine the right information with the right opportunities. Information strategy is increasing in importance and will assist firms in building a competitive edge.

Information has always been at the heart of organizations. While always vital, the increasing availability of various types of information has led to its growing organizational importance. Only within the last few years has the availability of information become such that managers have been able to obtain it at the time and place when they need it. Although much information has to be sifted to identify key information which is timely and complete, those managers that have it and know how to use it achieve a form of leverage over competing firms which do not possess similar information. Utilizing that latest and best information for aggressive management is prudent, if not imperative, in view of today's realities.

Given the importance of information, it is critical for an organization not to lag behind competitors in the development and utilization of information resources. Often, it takes years of lead time to develop an efficient information resource. For a lagging competitor, the race is likely over about the time this critical distinction sets in. The importance of organizational information is not going to lessen over time. As more firms think competitively, their attitudes toward information must change. They must come to think of information as a strategic asset - an asset that becomes the enabler of their business plans.

The economic gap between those which do and do not possess and employ information resources effectively will likely widen appreciably in the 1990 s and beyond. Only those managers who best understand this impact and direct their organizational resources in such a way as to best utilize information as a productive asset are likely to survive in an increasingly competitive global environment.

Journal of Business Strategies, Volume 7, Number 1 (Spring 1990) 
The trust of this article is twofold. First, it is advocated that information should be added to the list of the traditionally accepted factors of production. Second, an information protection decision model coupled with a classification scheme based on the economic value of differing types of information to the firm is presented.

\section{Information as a Factor of Production}

Incorporating information as a strategic corporate resource means managing a dynamic balance between the conceptual thinking of economists and managers. Economists have generally grouped productive factors into three broad categories: land, labor and capital. These factors have been viewed as the necessary inputs to any productive process. Land had been used to represent the input of raw materials which are derived as "gifts of nature;" labor the efforts of man; and, capital the input of man-made resources, such as machinery. Usually, money is added to the process as a means of facilitating trade, thereby providing some common denominator for valuation between the inputs and the output of the firm.

These inputs, or factors of production, have generally been viewed as substitutes for one another, tradiitionally assumed to be substitutable for one another at some diminishing rate of return. Thus, the use of labor could be increased and substituted for inputs of capital or land. Due to the scarcity of these inputs, however, a continual increase in the amount of labor applied to a productive process (while land and capital remain fixed) result in less and less output per unit of labor added. Even if labor were extremely cheap, diminishing returns will eventually be reached where further increases in output can only be obtained by increasing the input quantities of land or capital.

A primary concern of theoretical economists and practicing managers is the optimal allocation of resources under their control. They are concerned with producing the highest possible level of output (utility) given the productive resources available. This translates into using the firm's factor endowments in the most efficient way possible - finding the best fit of input combinations to accomplish the productive task. Information inputs which enhanced the productive process are a key organizational resource, and as such should be viewed as a factor of production.

Management theorists have extended the list of factors of production that was originated by economists. Many management scholars subscribe to the ideas of Frederick W. Taylor [4]. That is, they accept the proposition that management makes a unique contribution to the productive process. As a result, they contemporarily include management talent or entrepreneurial ability as a fourth basic factor of production, in addition to land, labor, and capital. This additional factor is usually defined in terms of the professional managerial skills and the necessary risk-taking that is involved with innovation and ownership of a successful business enterprise. Thus, managers would list land, labor, capital, and management or entrepreneurial ability as the factors of production which are under their control.

The inclusion of information as a productive input should not entail as great a conceptual leap for managers as for economists. As land, labor, and capital are all 
tangible inputs, it is easy for both economists and managers to recognize their value to the productive process. Management and entrepreneurial ability are far less tangible and are, therefore, more difficult to evaluate. But, because managers have already accepted management and entrepreneurial ability (relatively intangible factors), they should be more open to the concept of information as a productive input. Information however, possesses special characteristics which makes it unique. It is these special characteristics which should be understood if information is to be utilized and handled properly in the context of a factor of production.

\section{The Special Nature of Information}

Information is unlike any of the other productive inputs in many important aspects. These differences cause the need for decision-makers to re-evaluate the way in which productive factors are combined to produce goods and services. There may also be an impact on those that own the other factors of production, since the way in which the other inputs are allocated may be greatly altered as information use, flows, and values are altered.

Some of the salient characteristics of information are outlined in an article by Harlan Cleveland in the Futurist ([1], pp. 34-39). We have drawn on Cleveland's work, but have expanded and modified his thoughts. These extensions represent an effort to develop a framework to better guide managerial thought with regard to the nature, use, abuse, and safeguarding of information within the corporate environment. Within this expanded framework, information is viewed as simultaneously expansible, compressible, substitutional, transportable, shareable, and diffusive. These unique features of information are discussed below.

\section{Information is Expansible}

Most information tends to expand with use. Thus, as information is used, even more is generated. On the surface, this attribute may seem to be of little consequence. However, when the idea is applied to the efficient use of productive inputs, the special nature of information as a factor of production may be seen. All of the other factors of production are viewed as being scarce - that is, there is a limited supply of these inputs at any point in time. Moreover, few of the traditional resources are selfrenewing, much less self-generating. If information expands with use, it must not be viewed as being a scarce input, but rather an input of potential glut.

The only limits on the use of information would be the capacity of users to analyze, store, and retrieve it. However, even the limitation of analytical ability may diminish as artificial intelligence is further developed. The non-scarce nature of information must bring about a re-thinking of the dimensions associated with the calculus of utility maximization and cost minimization.

\section{Information is Compressible}

It is possible to concentrate, integrate, or summarize vast amounts of information for easier handling. Through the selection and compression of information into 
knowledge and wisdom, some of it is necessarily lost. The compression process, while necessary, is also a potential source of error, for the compression process eliminates information which may ultimately be needed. Managers must familiarize themselves as to the value of their information holdings (just as they know the worth of their tangible assets) in order to be able to distinguish the important from the trivial and preserve that which is needed. Further, managers must be able to retrieve previouslydiscarded information should it become viably important to the firm.

\section{Information is Substitutional}

The evolution of the mental process which allows managers to think of information as a factor of production will also cause them to grasp the idea that information can be substituted for land, labor, capital, entrepreneurial ability and management. In many cases, managers will come to the realization that information can be substituted for those other, often more expensive and less substitutional, factors of production. For instance, when the other resources are used more efficiently (i.e., less of the resource is used due to the input of new information), the net result will be a substitution of information for other factors in the productive process.

\section{Information is Transportable}

Using telecommunications technology, information can be transported at the speed of light! Thus, is provides a lightning response time for decisions. Also, information movement can be a strategic competitive tool in that its ease of movement does well what physical distribution often does poorly. With information, managers are not faced with the problem of physical transportability associated with the other factors of production. While some cost is involved in the "transportation" of information, its speed and lack of physical bulk should keep this cost relatively low.

\section{Information is Shareable}

The premise that information can be easily shared should cause a change in managerial thought. With information, managers must not think in terms of traditional exchange transactions, where one party gives up something of value in exchange for something else of value. Information is shareable. That is, I may give information to you without losing it myself. For example, if information is shared, we both have it my stock is not diminished because yours is increased. In fact, the same information can be sold, bartered, or otherwise exchanged.

\section{Information is Diffusive}

Information tends to leak. It is difficult to contain information as one would think of containing a physical object. Because information lends itself to diffusion, the issues of secrecy, property rights, and confidentiality are potentially called into question. However, since information is easily transported, potential unauthorized, as well as authorized, users can have ready access to it. Therefore, processes must be established to deny or limit the pilferage of information by persons or organizations 
which the owner wishes to restrict from access. That is, ways must be found to secure stocks of information much in the same manner as the other factors of production, but these methods must not be overly restrictive in its legitimate transportation.

Policies which are aimed at the husbanding of the other factors of production have been given considerable attention by prudent strategic managers. For example: personnel policies exist in an effort to retain and further develop an organization's "human capital." Warehouses are built to house the inventories of a firm's raw materials, finished goods, and other property. Extensive procedures have been developed to limit pilferage of these resources. Elaborate investment models and programs have been developed to protect the capital investment of the firm. It does appear, however, that the development of models which could help managers formulate plans and procedures for the protection of the firm's information resource are in a state of relative infancy. Because of the special nature of information, the models which have been developed for the protection of a firm's other resources are generally not directly applicable.

\section{Safeguarding the Information Source}

Many of the aspects which make information unique among the factors of production necessarily lead to the conclusion that information is relatively difficult to safeguard. This conclusion is supported by the current legal turmoil surrounding the meaning, application, and enforcement of copyright laws regarding modern forms of intellectual property, such as computer software. It is simply not an easy task to protect the intellectual property of a firm, whatever form it may take. While corporations would like to be able to build a protective wall around their intellectual property, much as a fence is built around a factory or a stockpile of coal, the intangibility of intellectual property makes the task futile. To date, no one had developed a truly effective safeguard against the "leakage" of information.

Does this mean that managers should not try to safeguard information? Quite the contrary! However, two facts should be borne in mind. First, it is not presently possible to totally prevent information leakage. Therefore, managers must factor the costs of leakage into their planning process by realizing that any information advantage is likely to be compromised. Second, managers should be aware that not all information is worth protecting. This realization calls for a conscious managerial decision to identify when the information possessed by the firm possesses sufficient value to warrant the expense and effort involved in attempting to safeguard it.

To help managers decide which information is worth protecting, a bi-polar model of information value is presented in Figure 1. The proprietary nature of information is plotted along the horizontal axis of the model. Ubiquitous information is defined to include that information which is readily available to anyone. Propriety information, on the other hand, is defined to include that information which was generated specifically for use by the firm (usually at considerable expense and effort). Ubiquitous information lies at the right extreme of the horizontal axis, while proprietary information anchors the right side of this axis. Values of the information to the firm 
are measured vertically. The left vertical axis represents the value of the information to the firm or the estimated cost of gathering it. Alternately, the right vertical axis represents either the value of information to the firm's competitors or the value of safeguarding information. Notice that the scales of value are reversed on the two vertical axes.

\section{Figure 1}

\section{The Information Protection Decision Model}

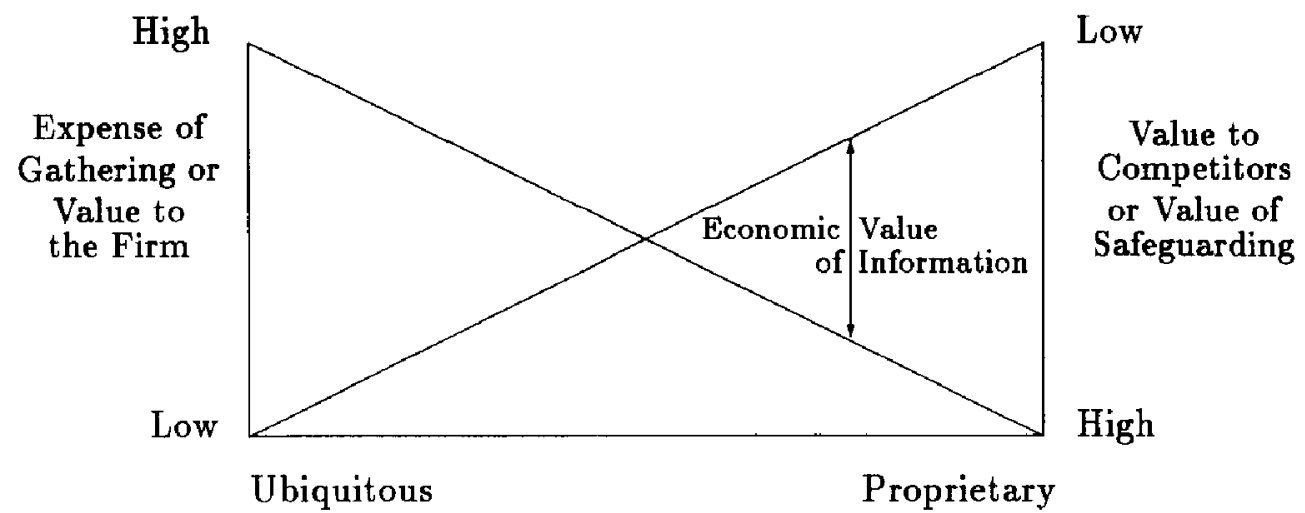

There are two relationships shown in Figure 1. The first is the relationship between the value of information to the firm or the cost of gathering it and the nature of information plotted on a continuum from ubiquitous to proprietary. Thus, the higher the value of information to the firm or the cost of gathering it, the more proprietary the information becomes. The second relationship is between the value of information to competitors, or the expense of safeguarding, and the nature of information. This relationship lies on the ubiquitous-proprietary continuum. Here, also, the higher its value to competitors or value of safeguarding, the more proprietary the information becomes. Figure 1 depicts these two relationships as being linear for illustrative convenience only - indeed, it is very probable that they are not.

In order for managers to reach decisions as to which information they should attempt to safeguard, they must operationalize the relationships described above and presented in Figure 1. This will necessarily entail the assignment of dollar values to the variables described on the vertical axes. Thus, any time that the dollar value of information gathering, or the dollar value of the information to the firm, exceeds the dollar value to competitors or the dollar value of safeguarding the information, it becomes worthwhile for management to spend any amount up to this difference to safeguard their information. Thus, the vertical distance between the two functions shown in Figure 1 represents the dollar amount that management should be willing to spend to safeguard information. This difference will be referred to as the "economic value of information to the firm."

Operationalization of the Information Protection Decision Model can help managers in two ways. First, it assists managers in separating information which should 
and which should not be protected. Second, managers will realize that from an economic standpoint, a large portion of the information which is possessed by the firm is not worth protecting.

In actual use the model presented in Figure 1 may be unwieldy for many firms. Therefore, to simplify the process, items of information may be classified into one of the four categories depicted in Figure 2. The military and many corporations have classified their important information for many years. However, many of these classification schemes have not been economically-based. The key requirement that must be met within the author's classification scheme is that items of information be classified solely on the basis of its economic value to the firm. Information may therefore be classified as Platinum, Gold, Silver, or Bronze, as illustrated in Figure 2.

\section{Figure 2}

\section{Classification of Information Based on} its Economic Value to the Firm

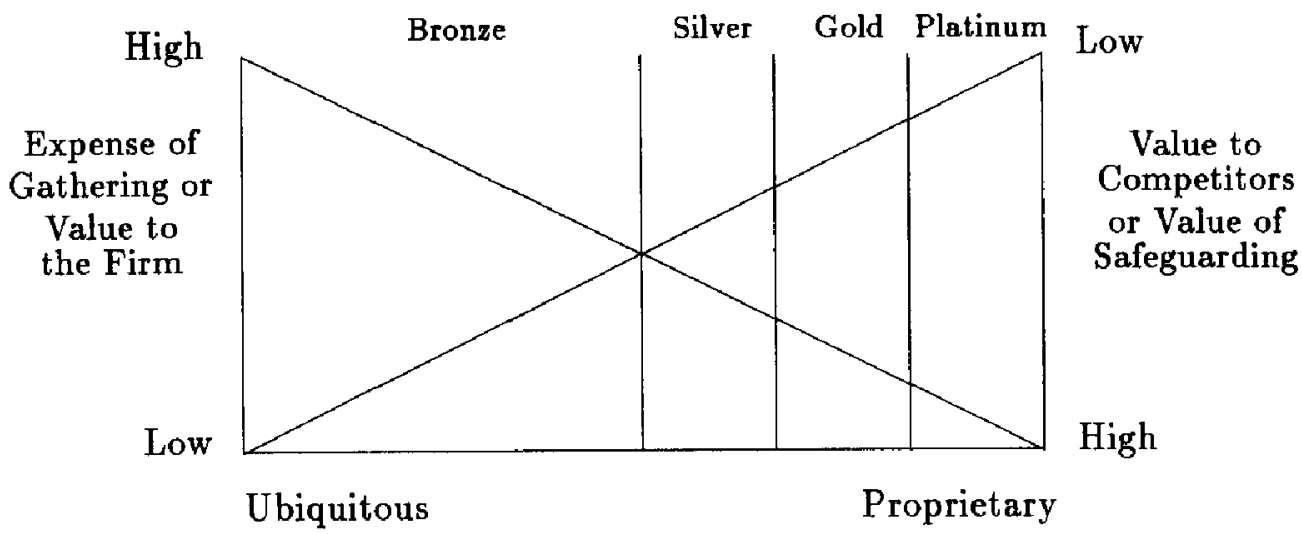

The classification scheme which is presented in Figure 2 allows managers to treat the various classes of information separately with regard to the expenditure of funds for the safeguarding of each class of information. Obviously, Platinum information has the highest economic value to the firm, and every effort should be made to safeguard it from unwarranted diffusion. At the other extreme, Bronze information is of little economic consequence to the firm. Due to its low economic value of information to the firm, such information may be handled casually with little, if any, expenditure or effort being made to safeguard it.

\section{Implications}

Managers must adjust to this new way of thinking and recognize that information is one of its important productive inputs. Depending on its economic value to the firm, information may require protection as a potential marketable output of the organization. In making their adjustment, managers will also have to reconsider the nature of the managerial process. Thinking of information as a peripheral activity, 
often relegated to a staff slot, is no longer viable. Information gathering, processing, and dissemination is fast becoming a key activity of many organizations. The more traditional functional activities, such as finance, marketing, and manufacturing, are shifting in importance as the global information-based society grows.

The cloistered nature of the information function is certainly fading as it is being reshaped by both user needs and corporate realities. In this context, greater strides must be made in establishing uniform protocols allowing for the total integration of information into the organizational structure. The past privileged status and attendant mobility of "computer experts" is proving perishable with the explosion of information technology and the growth of computer literacy among more and more managers. Out of necessity, information managers will have to move toward a way of thinking which places them more in tune with the reality of new organization structures. The day may be at hand when top level managers will no longer place control of such valuable corporate assets in the hands of a "computer expert" who may have little knowledge or understanding of the strategic implications regarding the operations of the organization. This is not an easy change. It necessitates a remodeling of the firm - a remodeling to a vastly different conceptual model which recognizes today's realities. As Edwards suggests, "... it's becoming clear that the successful organizations will be the ones which manage information most effectively." ([2], p. 125)

A study by Feldon indicates that organizations with "... formal business and systems plans and programs to plan, organize, monitor, and control the[ir] information resources outperformed [other firms] by 300 percent." ([3], p. 18) Feldon also underscores that firms which effectively utilize their information resources can leverage their other factors of production to financially outperform their competitors.

Other questions regarding the use of information as a productive input should be addressed. For example, if information can supplant the other factors, what will happen to the value of the other factors? If their demand is lessened, their worth as productive assets is likely to be cheapened. Since the United States is considerably better endowed than many nations with generous amounts of land, labor, capital, management and entrepreneurship than many other nations - yet, is on par with, or perhaps behind, many other nations in terms of information resources - will the U.S. economy be weakened in head-to-head competition in the world market?

As the value and use of information in the productive process increases, smart managers should strive to retain or increase the value of other productive assets. These managers will weave information into the fabric of their production function. This new fabric should possess a symbiotic result, wherein all factors, including information, collectively operate to produce more efficiently, while increasing in value.

\section{Conclusions}

The many unique aspects information must be recognized as it becomes more important as a factor of production, along with land, labor, capital, and management or entrepreneurial ability. Some changes in managerial thinking are called for, especially 
with regard to the safeguarding of information as a corporate asset. Any dislocations, however, can be minimized through planning and adjustment of conceptual models to take into account the growing importance of organizational information.

Based on a recognition of information as a major factor of production, managers at all organizational levels, but under the impetus of top management, must formulate and implement a new organizational model which recognizes the implications and the unique characteristics of information: expansibility, compressibility, substitutability, transportability, its diffusive nature, shareability, and recognition as to which information requires safeguarding. This mental revolution, similar to that which was called for earlier this century when Taylor proposed that management be viewed as a separate factor of production, should result in a new way of thinking about the nature of organizations, the purposes which they serve in the economy, and the manner which they serve in society as a whole. Furthermore, this new strategic vision about the role of information must be woven into the fabric of the organization and not just a passing fancy.

Those managers which recognize that information is a productive factor on a global scale and subsequently take action to alter their conceptual models will be in the best position to take advantage of the potential opportunities that are a by-product of this change. The firms that seize this opportunity to renew themselves are likely to prosper and lead the way into the twenty-first century.

\section{References}

1. Cleveland, Harlan. "Information as a Resource," The Futurist, Vol. 16 (December 1982), pp. 34-39.

2. Edwards, Morris. "Information Wars: Where East Meets West," Infosystems, Vol. 29 (September 1982), p. 125.

3. Feldon, O. A. "IRM and the Bottom Line," Infosystems, Vol. 28 (October 1981), p. 18.

4. Taylor, Federick W. The Principles of Scientific Management. New York: W. W. Norton Co., Inc. (1911). 